\title{
How does a woman experience bulimia nervosa? the link between bulimia nervosa, low self-esteem and insecure attachment: a phenomenological approach
}

\begin{abstract}
This case study aims to explore the link between bulimia nervosa, low self-esteem and insecure attachment through the experience of a bulimic young woman with symptoms of anxiety, who engaged in three years of psychodynamic psychotherapy. Based on the literature which underlines that eating disorders are usually manifested in people with insecure attachment patterns and low self-esteem, we used Interpretative Phenomenological Analysis in order to examine the experience of this woman. The sessions were recorded and were analysed in four different stages. Firstly, we focused on the transcript and studied it in terms of content and use of language, by making initial notes in order to study the way she contextualized her experience and the phrasing she used to describe it. Secondly, we returned to the transcript and extracted emerging themes from the initial notes and the woman's narrative. In the next stage, our goal was to examine the emerging themes and detect the conceptual similarities and links that we found. We attempted to establish a thematic structure that would allow us to highlight converging ideas. Lastly, once the text has been analysed and studied thoroughly, a final table is produced that summarises the significant themes, as they have arised from our analysis, and they are discussed in relation to existing literature.
\end{abstract}

Keywords: bulimia, self-esteem, attachment, psychodynamic psychotherapy, interpretative phenomenological analysis
Volume 9 Issue 5 - 2018

\section{Pilios-Dimitris Stavrou}

Department of Psychology, University of Athens, Greece

\begin{abstract}
Correspondence: Pilios-Dimitris Stavrou, Department of Psychology, University of Athens, Athens, Greece Laboratory of Clinical Psychology, Psychopathology and Psychoanalysis (PCPP), University Paris Descartes, Sorbonne, Paris, France, 2 I G. Papandreou Street, 15773, Zografos, Athens, Greece,Email stavroupd@gmail.com
\end{abstract}

Received: October 04, 2018 | Published: October 22, 2018

\section{Introduction}

\section{Bulimia nervosa}

Bulimia nervosa is among the major eating disorders (EDs) classified in the Diagnostic and Statistical Manual of Mental Disorders, $5^{\text {th }}$ version (DSM-5). ${ }^{1}$ It is a serious, potentially lifethreatening eating disorder characterized by a cycle of bingeing and compensatory behaviors such as self-induced vomiting designed to undo or compensate for the effects of binge eating. ${ }^{2}$ This ED affects $1-1.5 \%$ of females and there is a 10:1 ratio of females to males suffering from the disorder. ${ }^{1}$ It is associated with significant physical and psychological consequences, as well as a high mortality rate, mainly caused by serious medical complications and suicide. ${ }^{3}$

Link between eating disorder, insecure attachment and low self-esteem

\section{Eating disorder and attachment}

The onset of EDs typically occurs during adolescence and early adulthood, between the ages of 15 and $25,,^{3-6}$ periods of time when family dependence is the most important. Eating disorders, like bulimia, occupy a crossroad between childhood and adulthood; between psychic and somatic; between the individual and the social Beyond the repetitive and stereotypical nature of the symptom, EDs reveal a specific dynamic of relationships and investments. It is one of the essential contributions of psychoanalysis to have shown that the symptom hides as much as it shows and that it occupies a function in the psychic dynamic and the balance of the personality. According to Suldo \& Sandberg ${ }^{7}$ issues specific to this developmental period of adolescence and early adulthood should be examined as possible explanations for the onset and maintenance of eating disorders. In fact, many recent researches and reviews ${ }^{8,9}$ support that most of ED patients are insecurely attached and that EDs are statistically related to types of insecure attachment. It can be considered that attachment theory, originating from Bowlby's work ${ }^{10}$ can offer a comprehensive framework for understanding the individual and family characteristics contributing to the development of EDs in adolescence and young adolescence. In line with these studies, an important number of researchers confirm the attachment (particularly, insecure one) to be a "mediator" construct ${ }^{11,12}$ between ED and personality structure. Disturbed early relationship bond can play a role of absolute importance in predisposing, precipitating and maintaining ED pathogenic core, which is characterized by low selfesteem, depression, suffering caused in mismatching actual weight and ideal weight, and somatic-psychic disorders. ${ }^{13}$ In link with this Gamble \& Robert's ${ }^{14}$ results showed that the insecure attachment is associated with low self-esteem, dysfunctional attitudes, and negative attributional style.

\section{Eating disorder and self-esteem}

Bulimics like anorexics share characteristics like low self-esteem, a sense of ineffectiveness, and conflicts of identity and autonomy. ${ }^{15,16}$ According to Robson, ${ }^{17}$ self-esteem is "a sense of contentment and self-acceptance that results from a person's appraisal of their 
own worth, attractiveness, competence and ability to satisfy their aspirations." In a review of literature, Ghaderi ${ }^{18}$ concluded that low self-esteem not only puts women at greater risk for the development of an eating disorder but also serves to maintain an ED. Research shows that low self-esteem may be associated to insecure attachment, as individuals who have experienced secure attachment tend to be more self-confident and have higher self-esteem, while those with a history of insecure or avoidant attachment patterns are usually rated with lower self-esteem. ${ }^{18}$ It has been shown that low self-esteem is positively correlated to disordered eating symptoms in both boys and girls ${ }^{19}$ and is one of the most important factors in bulimic symptoms in college women..$^{20}$ A recent study of Mora et al..$^{21}$ also confirm the above researches and shows that having low self-esteem score, significantly increases the likelihood of having a high score on the scale of ED. Self-esteem appears to be a primary risk factor that may contribute to the development of other risk factors for eating disorders. For example, three separate research studies found that development of bulimia is predicted by perfectionistic tendencies and body dissatisfaction only among low self-esteem women, whereas women with higher selfesteem did not have these risk factors and accordingly did not develop bulimia. ${ }^{22-24}$ Additionally, studies which focused on the relationship between self-esteem and bodily dissatisfaction, showed a positive correlation between these two variables. ${ }^{25,26} \mathrm{~A}$ decrease in self-esteem contributes to poorer body image in young adult men and women ${ }^{27,28}$ and bulimic symptoms in women. ${ }^{23}$ Self-esteem can thus be considered as a major determinant of one's body image. Additionally, a recent study of Bégin et al. ${ }^{29}$ which focused on the link between both types of selfesteem (explicit and implicit) and eating disorders showed that the eating disorder group reports more body dissatisfaction and presents the weakest explicit and implicit self-esteem. More specifically, self-esteem includes two independent systems of information processing, the explicit self-esteem (ESE), and the implicit selfesteem (ISE) ${ }^{30-32}$ According to relevant research, ESE derives from rational, conscious, and controllable self-assessment, whereas ISE is automatic, unconscious, and uncontrollable self-association. ${ }^{33}$ Thus, the presentation of self-esteem obtained by Begins' et al. ${ }^{29}$ research is more a result of convergent self-esteem (low self-esteem, explicit and implicit), rather than divergent self-esteem (eg, low self-esteem and self-esteem). These results confirm those obtained by Vanderlinden et al. (2009), which showed that in women with eating disorders both types of self-esteem are concurrent.

\section{Bulimia and psychodynamic psychotherapy}

The different types of EDs can be considered as manifestations of deep psychological disturbances, which are rooted in the individual's past. An ED can be seen as the expression, at a given moment of subject's evolution, of the psychic difficulties they encounter or they met in the past. In link with this, the symptom can be conceived as a consequence of dysfunctional psychological processes. To understand the underlying causes of this eating disorder and the nature of the difficulties that gave birth to it, specialists have turned to psychotherapy, which allows clinicians to approach the emotional suffering hiding behind the symptoms. In detail, psychotherapy offers an opportunity for clinicians and patients to explore the inner reality of the sufferer, and thus comprehend the subjective experience of this disorder. Although many studies advocate the use of cognitivebehavioral therapy (CBT) for patients with bulimia nervosa and binge eating disorder, ${ }^{34}$ it has be shown that a substantial number of such cases do not recover with CBT alone. ${ }^{35}$ There is an extensive literature describing psychodynamic approaches when working with bulimia nervosa and binge eating disorder, ${ }^{36}$ where the therapeutic relationship is central. ${ }^{37,38}$ Psychodynamic psychotherapy is characterized by being much broader in its focus than CBT, prescribing a nondirective, unstructured approach and dissuading direct instructions to the patient. Symptoms are considered inseparable from client personality structure and, in contrast to CBT, the target of interventions are feelings, defences, and the psychodynamic function of the symptoms. According to Thompson-Brenner \& Westen, ${ }^{39}$ whereas CBT therapy is associated with more rapid remission of eating symptoms, psychodynamic interventions and increased treatment length predict better global outcome across treatment modalities, suggesting the importance of integrative treatments for the broad range of pathology seen in patients with bulimic symptoms. A research of Gaudriault $\&$ Carole Guilbaud ${ }^{40}$ found that over three-quarters of the bulimic subjects progressed during their psychotherapy in terms of subjective expression additionally. Poulsen et al. ${ }^{41}$ showed through their study that the majority of the clients reported positive experiences that were directly related to the specific characteristics of the psychodynamic approach. Psychodynamic psychotherapy can thus enable the therapist to explore the client's deep psychological disturbances and in the case of EDs, psychodynamic psychotherapy focuses on the emotional suffering hiding behind the symptoms: insecure attachment, lack of self-esteem, inability to take responsibility for oneself, malfunctioned decision-making processes, denial towards personal growth, inability to enjoy the present.

\section{Case study}

\section{Case introduction}

Antigone (not her real name) is a 30 years old Greek woman, working as an IT specialist in a shipping company. She visited our practice requesting support as she relapsed in bulimic episodes. Her ED had manifested when she was 17 years old in the form of bulimic episodes. The episodes went on for two years until she revealed her condition to her mother, who convinced her to ask for professional help. She was hospitalized in a private ED specialty treatment center for a three months period, where she was diagnosed with Bulimia Nervosa and Generalized Anxiety Disorder. As part of her treatment, she received multisystemic therapy, assertive group therapy, and Cognitive Behavioural Treatment, a program designed by a multidisciplinary team consisting of psychiatrists, psychologists, doctors and nutritionists. Following her release from the hospital, Antigone completed a degree in business administration and started working. She moved to her own apartment and in the age of 25 entered a relationship with a colleague which continues to this day. According to her, she had never relapsed in the past after her release to the hospital, until two months before visiting our practice. In her own words, 'at first I thought, oh it's just a onetime thing, you know, because of the pressure at work, or umm, because I had a fight with Nick [her partner], but then, umm, it went on, and umm, I could only sleep if I had made myself sick before going to bed, or I could only concentrate at work if I had made myself sick beforehand, so I realised I needed help.'

\section{Psychosocial history}

Antigone was raised in Athens by her mother, a science teacher, and her father, a finance consultant, along with her two sisters, five and six years younger than her respectively. At the beginning of therapy she described her childhood as 'normal', and her relationship with her parents as 'cold and dysfunctional'. She mentioned she really 
loved her sisters but did not feel very close to them because of the age difference. When asked about her body image, Antigone mentioned she was preoccupied with her appearance since a very young age, and was dissatisfied with the way she looked. Feelings of body dissatisfaction intensified when she entered adolescence. During this time period her relationship with her parents deteriorated; 'My dad was absent most of the time and didn't pay any attention to me, he would only be interested in me when I would bring home my school grades. In primary school I was top of my class but in high school that changed, I was umm, less interested in school, and umm, I felt I didn't care anymore, my parents were mad, but I didn't care, I only wanted to go to the gym and hang out with my friends, and I remember dieting and trying all these different diets, umm like the chemical one, or the protein one, or the Atkinson one, umm... Basically I have tried every diet you've ever heard of'. Antigone's troubled relationship with food seemed to become the center of her life while simultaneously the relationship with her family deteriorated gradually. She experienced her parents as absent from her life and indifferent in everything except from her academic performance; we can assume that Antigone established an external locus of control, as her parents' affection and approval was dependent on her grades. As her grades dropped and her parents' attitude became more dismissive towards her, her obsession with her food intake became more prevalent; 'I would count the calories and stopped eating things that contained carbs or fat or sugar.. but that wasn't enough, I felt that I was fat and ugly and when those feelings would come up they were overwhelming and I didn't know what to do, so one night that I went to bed hungry and I was so hungry I couldn't sleep, so at like 2am or something, I still remember the time, I got up and ate so much, I don't remember exactly what but I remember I ate so much and felt full for the first time in months, but my stomach hurt so much after that, umm, I went to the bathroom and I didn't even have to try, everything just came out, and then I was able to sleep peacefully for the first time in a long time. I had found the way to stay slim and eat anything at the same time. I start feeling better about myself, and guys started hitting on me and I started, like, dating just like everyone else'. Antigone's description of her first bulimic episode is indicative of the body image issues she was struggling with, and allows for a glimpse of the low self-esteem she defined as 'an obstacle' herself. Meanwhile, she characterized her relationship with men 'problematic'. 'Since I can remember myself I was attracted to men older than me, I don't know, men my age seem too, umm, immature and stuff..' Her current partner follows the same pattern, as he is fifteen years older than her, a fact that was explored thoroughly during therapy.

\section{Interpretative phenomenological analysis}

Interpretative Phenomenological Analysis (IPA) is a qualitative research method that derives from the theoretical branch of phenomenology and hermeneutics. ${ }^{42,43}$ It focuses on experiential personal accounts and narrations of subjective experiences. ${ }^{44}$ In order to engage with the above principles, IPA draws from symbolic interactionism, which assumes that people's behaviours are a product of the meaning they prescribe to them and the meaning that emerges in the process of social interactions. ${ }^{45}$ Based on this, meaning is subjective and is constructed through an interpretative process that is flexible and constantly redefined. ${ }^{45}$ Combining principles of phenomenology, hermeneutic philosophy and engagement with subjective experience, IPA introduces an interdisciplinary way between different qualitative approaches to research. ${ }^{46}$ In line with phenomenological analysis, it allows researchers to examine subjective experiences and the meaning that individuals attribute to them. ${ }^{47}$ Due to its affiliation with discursive psychology, IPA accepts that research is fundamentally hermeneutic, as the researcher and the participant are engaging in a common interpretation of meaning, one that is shaped by shared cultural values. ${ }^{47}$

\section{Issues of ontology and epistemology}

The synthesis of different research approaches that is characteristic of IPA indicates the pluralistic nature of epistemological principles that define this approach. Indeed, IPA is focused on the experiential dimension of lived experience and the process of meaning-making that derives from such experiences. ${ }^{44}$ Additionally, 'it endorses social constructionism's claim that sociocultural and historical processes are central to how we experience and understand our lives, including the stories we tell about these lives' ${ }^{44}$ Under this perspective, IPA is located between experiential approaches such as descriptive phenomenology, and approaches of discursive nature, such as discourse analysis. ${ }^{48}$ In the case of experiential research methods, researchers focus on the experiences participants describe, and the way they make sense of these experiences. In the case of discursive approaches, the focus is on language as a tool for social action that co-cosntucts the social reality and the social world. ${ }^{48}$ As Reicher ${ }^{48}$ pointed out, the different epistemological stances that influence IPA '[they] have different philosophical roots, they have different theoretical assumptions and they ask different types of questions'. In regards to phenomenology, this philosophical approach is concerned with the structure of human experience and consciousness; in the premise that reality consists of objects and events ("phenomena") as they are perceived or understood in the human consciousness, and not of anything independent of human consciousness. This branch of epistemology, as it is understood today, derives from the work of Husserl. ${ }^{49}$ Husserlian phenomenology is opposed to naturalism and the theoretical principles of positivism. In detail, Husserl focused on lived experience and personal accounts of phenomena as experienced by the subject, rather than causal explanations. ${ }^{50}$ Thus, this philosophical perspective does not seek to contextualize or categorize its knowledge in a specific, predetermined context. Rather, it tries to depict and convey the essence of experience as seen by the person living it. Another major philosophical perspective that is widely used in qualitative research is hermeneutics. Originally, hermeneutics was developed as a method of interpreting biblical texts, and was established in western thinking as a philosophical foundation for the study of interpretation. ${ }^{51}$ Contrary to phenomenology, hermeneutics are located within a specific social, historical and cultural context; the topic of inquiry is studied from the perspective of the researcher, and thus is affected by the preconceptions that arise from being the member of a cultural, social, political group. ${ }^{52}$ It assumes that we, as researchers, can never be free of the language we think and speak in, and therefore all the questions we pose and all the answers we produce are embedded in our culture. These differences between phenomenology and hermeneutics were bridged by Martin Heidegger, who approached both perspectives as integral, essential parts of our way of studying human experience; he saw interpretation as a dynamic process that links the interpreter and the object of interpretation. ${ }^{52}$ According to Heidegger, all human experience is interpretative, meaning that phenomenology could be approached as a way to interpret one's experience, and as such hermeneutics are a prerequisite to phenomenology. ${ }^{50}$ Moran explained that: 'Phenomenology is seeking after a meaning which is perhaps hidden by the entity's mode of appearing. In that case the proper model for seeking meaning is the interpretation of a text and 
for this reason Heidegger links phenomenology with hermeneutics. How things appear or are covered up must be explicitly studied. The things themselves always present themselves in a manner which is at the same time self-concealing. ${ }^{50}$ Based on this, our understanding of human experience is always rooted in our existing knowledge of the world; 'Interpretation is grounded in something we have in advance'.$^{53}$ Drawing from these epistemologies, qualitative research in psychotherapy engages in a dynamic process of exploring the human experience from a non-positivist perspective and offering a deep, rich study of our understanding of subjective experiences. It is for the above reasons that we chose IPA as a research methodology; we were not interested in providing a positivist, naturalist study of the phenomenon of bulimia that would focus on causality or reduce a complex human experience to numeric data. Rather, we seeked to explore the personal account of a woman who has experienced bulimia, and engage in a dialogue that would create a space for her to communicate a detailed account of her experience, guided by her memories, feelings and concerns. This way, we opened up an interpretative avenue for her to reflect on her experience and attempt to make sense of it. Through her narrative and attempt to produce meaning of her experiences, we seeked to understand how her experience of bulimia came about and what parts of her past had contributed to its manifestation according to her.

\section{Content analysis}

Our initial approach to this project was to record the therapy sessions with Antigone and use the transcripts and our personal notes to explore the way she made sense of her experience. To organize the material in a way that would allow us to engage dialectically and make sense of it, we worked in four different stages; firstly, we focused on the transcript and studied it in terms of content and use of language. Indeed, Antigone seemed to focus on specific themes that have shaped her experience, and they are prevalent in the way she contextualized her experience and the phrasing she used to describe it. Focusing on them, we made some initial notes in order to engage personally with the material and understand the meaning it has been attributed to it. In certain occasions some of the notes were of interpretative nature, as we commented on what we could understand from our point of view. Secondly, we returned to the transcript and extracted emerging themes from the initial notes. Here, we attempted to capture the meaning Antigone was communicating by formulating thematic phrases that were linguistically proximal to her original words, but also offered a conceptual understanding. These phrases represented the emerging themes in Antigone's narrative, as we conceptualized them following the initial study of the transcript. In the next stage, our goal was to examine the emerging themes and detect the conceptual similarities that we found; every theme followed a pattern and in certain occasions these patterns were intertwined. We attempted to establish a thematic structure that would allow us to highlight converging ideas. Lastly, once the text has been analysed and studied thoroughly, a final table is produced that summarises the significant themes, as they have arised from our analysis, and they are discussed in relation to existing literature.

\section{Initial stage}

We read the whole transcript a number of times. We considered useful to record some observations and reflections about the interview experience, as well as thoughts and comments of significance, in a separate reflexive notebook. This was accompanied by a detailed textual analysis that starts with writing notes and comments on the transcript. The process of engaging with the transcript involves focusing on content, use of language, context and interpretative comments arising from the engagement with the material.

\section{Therapy: initial comments (extract)}

\section{Second stage}

We transform the initial notes into emerging themes Table 1.

Table I Developing emergent themes (extract)

\begin{abstract}
Exploratory comments
I have trouble focusing at work. My problems started again and it feels really hard.... and it's like I have to go back into my past. Like l'm reliving problems l've had before. I feel anxious, lost and incapable.
\end{abstract}

Original transcript

Facing the past-upheaval Dealing

with painful emotions

Dysfunctional childhood family Dysfunctional relationship with the father Dysfunctional body image

Bulimia as a mean of support

Dysfunctional adult relationships with men

Low self-esteem Feelings of inferiority and incapacity Insecure attachment
I feel good only when I make myself sick. I feel that I don't deserve many things. I experience stress constantly. I feel sad at home and at work. I've started feeling like I did back in school, but when I was younger I never talked about my problems....my parents didn't ask me very often. My father didn't talk to me very often and my relationship with my mother and my sisters felt really cold. I didn't have many friends. I don't have now either. In the past I tried to be involved with some guy as much as possible. I felt and I feel more secure when I have a boyfriend. But even when I am with someone my feelings about myself don't change. 


\section{Third stage}

We examined the emerging themes and clustering them together according to conceptual similarities. We looked for patterns in the emerging themes and produce a structure that is helpful in highlighting converging ideas Table 2 . Through the psychodynamic psychotherapy a link between self-esteem and attachment is observed.

Table 2 Initial clustering of themes

\begin{tabular}{lll}
\hline $\begin{array}{l}\text { Focus on eating } \\
\text { disorder }\end{array}$ & $\begin{array}{l}\text { Relationships } \\
\text { with others }\end{array}$ & Self-esteem \\
\hline $\begin{array}{l}\text { Intensity of engagement in } \\
\text { eating disorders behavior }\end{array}$ & $\begin{array}{l}\text { Dysfunctional } \\
\text { family dynamics }\end{array}$ & $\begin{array}{l}\text { Feelings of inferiority } \\
\text { and incapacity }\end{array}$ \\
$\begin{array}{l}\text { Positive experience of } \\
\text { eating and becoming sick }\end{array}$ & $\begin{array}{l}\text { Insecure } \\
\text { attachment }\end{array}$ & Feeling of anxiety \\
$\begin{array}{l}\text { Eating and becoming sick } \\
\text { as means of dealing with } \\
\text { painful feelings }\end{array}$ & $\begin{array}{l}\text { Dysfunctional } \\
\text { adult } \\
\text { relationships }\end{array}$ & $\begin{array}{l}\text { Constant self-criticism/ } \\
\text { being overly critical of } \\
\text { herself }\end{array}$ \\
& $\begin{array}{l}\text { Being unable to accept } \\
\text { compliments, Minimizing } \\
\text { her positive qualities, } \\
\text { Bulimia as a support system } \\
\text { of her own abilities. }\end{array}$ \\
\hline
\end{tabular}

\section{Final stage}

A table of themes is produced. This table shows the structure of major themes and subthemes. It is a final table of themes Table 3.

\begin{tabular}{|l|}
\hline Superordinate theme I -focus on bulimia \\
\hline Bulimia as an affliction \\
\hline 'This feeling of complete despair [ ] if I could change the way I am' \\
\hline Intensity of engagement in bulimia \\
\hline 'There are moments I can't stop eating and after that all I want is to sick' \\
\hline Bulimia as a support \\
\hline 'When I eat and sick, I feel better and less stressed.' \\
\hline Superordinate theme 2 -focus on self \\
\hline Perception of self \\
\hline $\begin{array}{l}\text { 'Feel l'm not good enough. Thoughts like oh l'm worthless or no one } \\
\text { cares about me.' }\end{array}$ \\
\hline
\end{tabular}

\begin{tabular}{|l|}
\hline Superordinate theme 3 -focus on relationships with others \\
\hline Relationship with the family \\
\hline 'My family never appreciate me' \\
\hline Relationship with others \\
\hline 'My relationships are unsuccessful' \\
\hline
\end{tabular}

\section{Narrative account (extract)}

The engagement with bulimia was portrayed metaphorically as attachment evoked by love 'My love and support is food' [ ] 'All I want is eating and after making myself sick'

\section{Discussion}

The process of observing and analysing the material of Antigone's initial therapy sessions through text allowed us to investigate her experience of bulimia and the way she signified this experience. She discussed the nature of her relationship with her family and focused on her relationship with her father. When talking about it, feelings of abandonment and rejection became evident; she used words such as absent, lack of attention, need for affection. Moreover, she described her mother as absent as well, and referred to their relationship as cold. The literature confirms that EDs are usually manifested in people with insecure attachment patterns. There are many recent researches and reviews ${ }^{8,9}$ which support that most of ED patients are insecurely attached. Insecure attachment develops in cases when the child's needs are not fulfilled. Antigone has made it clear that a big part of her emotional needs, such as her need for affection and intimacy had not been met by either of her parents when she was growing up. This has affected the way she experiences the world; Ainsworth ${ }^{54}$ noted that although attachment bonds form in the early stages of life, they affect one's development across the lifespan.

This is supported by relevant research, which demonstrates that the quality of attachment to parental figures affects children's social and emotional development, and an insecure attachment can leave children feeling unimportant and abandoned. ${ }^{55}$ Accordingly, Antigone described she has been struggling with such feelings her whole life, and explained that they have negatively influenced her social and romantic life as well. More specifically, she seems unable to feel safe and protected in the relationships she forms, and she communicates feeling like a burden to the men she dates. Her difficulty in forming successful romantic relationships could be rooted in the insecure attachment she formed with her father; indeed, relevant research suggests that positive father involvement and nurturant fathering often translated as the father acting as a secure base for his child - are associated with greater self-esteem in daughters. ${ }^{56}$ As it is expected, securely attached people hold positive views of themselves and others. ${ }^{57-59}$ Conversely, individuals who have received inconsistent support from their caregivers internalize a negative mental model of self, and a positive model of others. ${ }^{60}$ As we saw through her words, Antigone experiences a negative model of self and struggles with uncertainty and anxiety regarding acceptance in relationships. Her past experience with rejection in the relationship with her father seems to be reproduced in every relationship she forms, as she is unable to change this pattern. Thus, insecure attachment in the case of Antigone seems to be interrelated with her low self-esteem and negative self-concept. Research on EDs among women suggests that low self-esteem correlates with the manifestation of EDs, ${ }^{18}$ and links self-esteem to insecure attachment. Sroufe ${ }^{61}$ investigated attachment and development in a 30-year longitudinal study, evaluating participants from birth to adulthood. Results indicated that children with secure attachment histories were consistently rated as more self-confident, higher on self-esteem, and more "ego-resilient" than those with either a history of resistant or avoidant attachment. Additionally, Salzman ${ }^{62}$ demonstrated that female college-aged adolescents who are securely attached are also likely to have healthy self-esteem and higher overall well-being compared to those who are insecurely attached. Likewise, Mora et al. ${ }^{21}$ supported that women are more likely to be diagnosed with EDs when they suffer from low self-esteem and negative self-image. Antigone has indeed expressed 
her dissatisfaction with her body image, which is a characteristic of bulimia, but also with her as a whole as well; throughout therapy she had explicitly stated that she does not feel 'enough', 'good enough', and she constantly feels 'incapable'. These statements are indicative of someone who experiences feelings of inferiority and resorts to bulimia to feel they are in control; Antigone stated she only feels good when she makes herself sick. Unable to perceive herself in a positive manner, she utilizes self-destructive behaviour to cover the feeling that she is not in control of her life.

The issue of bulimia nervosa in women is one that has been studied thoroughly, and yet it is such a complex and multidimensional condition that one cannot examine all aspects that define it. In the present case study we have focused on Antigone, a 30 years-old Greek woman who suffers from bulimia nervosa. The diagnosis took place when she was hospitalized in the age of 19 , and the bulimic episodes reappeared for the first time after she was released from the hospital two months prior to her visit at our practice. We used transcripts from the initial stages of her therapeutic journey to study the phenomenon of bulimia and its link to insecure attachment and low self-esteem. As we were interested in Antigone's subjective experience, her own account of bulimia, and the feelings that accompanied her narrative, we decided to use Interpretative Phenomenological Analysis to approach this case, in order to engage in an in-depth exploration of her experience. The analysis of the transcripts allowed for a better understanding of Antigone's experience, but it is not in any way an exhaustive analysis of the therapeutic process, or the transformation she experienced through therapy. Rather, it focuses on the link between bulimia, selfesteem and attachment, and attempts to connect these factors with existing literature on the matter. ${ }^{63}$

\section{Acknowledgments}

None.

\section{Conflict of interest}

The author declares that there is no conflict of interest.

\section{References}

1. American Psychiatric Association. Feeding and eating disorders Diagnostic and Statistical Manual of Mental Disorders $5^{\text {th }}$ ed. Washington, DC: American Psychiatric Association. 2013.

2. Network NEDA. National Eating Disorders Association. 2018.

3. Sullivan PF. Course and outcome of anorexia nervosa and bulimia nervosa In: Fairburn CG, Brownell KD, editors. Eating disorders and obesity: $A$ comprehensive handbook. Guilford Press, New York; 2002:226-230.

4. Corcos M. Approche psychosomatique des conduites addictives alimentaires. Dialogue, 2005;(3),97-109.

5. Hoek HW, Bartelds AI, Bosveld JJ, et al. Impact of urbanization on detection rates of eating disorders. American Journal of Psychiatry. 1995;152(9):1272-1278.

6. Woodside DB, Garfinkel PE. Age of onset in eating disorders. International Journal of Eating Disorders. 1992;12(1):31-36.

7. Suldo SM, Sandberg DA. Relationship between attachment styles and eating disorder symptomatology among college women. Journal of College Student Psychotherapy. 2000;15(1):59-73.

8. Gander M, Sevecke K, Buchheim A. Eating disorders in adolescence: attachment issues from a developmental perspective. Frontiers in psychology, 2015;6:1136.
9. Salcuni S, Parolin L, Colli A. Attachment research and eating disorder: a measurement perspective-literature review. 201722(3): 478-504.

10. Bowlby J. Attachment and Loss, London: Hogarth Press. 1969.

11. Keating L, Tasca GA, Bissada H. Pre-treatment attachment anxiety predicts change in depressive symptoms in women who complete day hospital treatment for anorexia and bulimia nervosa. Psychology and Psychotherapy: Theory, Research, and Practice. 2015;88 (1):54-70.

12. Milan S, Acker JC. Early attachment quality moderates eating disorder risk among adolescent girls. Psychol Health. 2014;29(8):896-914.

13. Galeazzi A, Meazzini P. Mente e comportamento. Trattato italiano di psicoterapia cognitivo-comportamentale. Firenze: Giunti. 2004 :601p.

14. Gamble SA, Roberts JE. Adolescents' perceptions of primary caregivers and cognitive style: The roles of attachment security and gender. Cognitive Therapy and Research, 2005;29(2);123-141.

15. Garfinkel PE, Garner DM, Goldbloom DS. Eating disorders: Implications for the 1990's. Canadian Journal of Psychiatry. 1987;32(7):624-631.

16. Katz JL. Some reflections on the nature of the eating disorders: On the need for humility. International Journal of Eating Disorders. 1985;4(4):617-626.

17. Robson P. Development of a new self-report questionnaire to measure self esteem. Psychol Med. 1989;19(2):513-518.

18. Ghaderi A. Review of Risk Factors for Eating Disorders: Implications for Primary Prevention and Cognitive Behavioural Therapy. Scandinavian Journal of Behaviour Therapy. 2001;30 (2):57-74.

19. McCabe MP, Vincent MA. The role of biodevelopmental and psychological factors in disordered eating among adolescent males and females. European Eating Disorders Review: The Professional Journal of the Eating Disorders Association. 2003;11(4):315-328.

20. Mora-Giral M, Raich-Escursell RM, Segues CV, et al. Bulimia symptoms and risk factors in university students. Eating and Weight DisordersStudies on Anorexia, Bulimia and Obesity. 2004;9(3):163-169.

21. Mora F, Rojo SF, Banzo C, et al. The impact of self-esteem on eating disorders. European Psychiatry. 2017;41 Supplement: S558.

22. Vohs KD, Voelz ZR, Pettit JW, et al. Perfectionism, body dissatisfaction, and self-esteem: An interactive model of bulimic symptom development. Journal of Social and Clinical Psychology. 2001;20(4):476-497.

23. Vohs KD, Bardone AM, Joiner TE, et al. Perfectionism, perceived weight status, and self-esteem interact to predict bulimic symptoms: A model of bulimic symptom development. Journal of Abnormal Psychology. 1999;108(4):695-700.

24. Joiner TE, Heatherton TF, Rudd MD, et al. Perfectionism, Perceived Weight Status, and Bulimic Symptoms: Two Studies Testing a Diathesisstress Model. Journal of Abnormal Psychology. 1997;106(1):145-153.

25. Henriques GR, Calhoun LG. Gender and ethnic differences in the relationship between body esteem and self-esteem. $J$ Psychol. 1999;133(4):357-368.

26. Mendelson BK, McLaren L, Gauvin L, et al. The relationship of selfesteem and body esteem in women with and without eating disorders. Int J Eat Disord. 2002;31(3):318-323.

27. Abell SC, Richards MH. The relationship between body shape satisfaction and self-esteem: An investigation of gender and class differences. Journal of Youth and Adolescence. 1996;25(5):691-703.

28. Gleason JH, Alexander AM, Somers CL. Later adolescents' reactions to three types of childhood teasing: Relations with self-esteem and body image. Social Behavior and Personality: an international journal. 2000;28(5):471-479. 
29. Bégin C, Boucher K, St-Laurent A, et al. L'estime de soi explicite et implicite chez des femmes souffrant de troubles des conduites alimentaires. Revue québécoise de psychologie, 2016;37(1):133-152.

30. Epstein S. Integration of the cognitive and the psychodynamic unconscious. American Psychologist, 1994;49(8):709-724.

31. Smith ER, DeCoster J. Dual process models in social and cognitive psychology: conceptual integration and links to underlying memory systems. Personal and Social Psychology Review. 2000;4(2):108-131.

32. Wilson GT. Cognitive behaviour therapy for eating disorders: Progress and problems. Behaviour Research and Therapy. 1999;37(suppl 1):S79S95.

33. Greenwald AG, Banaji MR. Implicit social cognition : attitudes, selfesteem, and stereotypes. Psychol Rev. 1995;102(1):4-27.

34. Fairburn CG, Harrison PJ. Eating disorders. Lancet, 2003;361;407-416.

35. Wilson TD, Lindsey S, Schooler TY. A model of dual attitudes. Psychological Review. 2000;107(1):101-126.

36. Appledorn K. Object relations and identity disturbance in bulimic women Dissertation Abstracts International: Section B: The Sciences and Engineering. 2000;60:6394.

37. Williams G. Internal landscapes and foreign bodies: Eating disorders and other pathologies. Duckworth, London. 1997.

38. Zerbe KJ. The crucial role of psychodynamic understanding in the treatment of eating disorders. Psychiatric Clinics of North America. 2001;24(2):305-313

39. Thompson-Brenner H, Westen D. A naturalistic study of psychotherapy for bulimia nervosa, part 2: Therapeutic interventions in the community. The Journal of nervous and mental disease. 2005;193(9):585-595.

40. Gaudriault P, Guilbaud C. Rorschach assessment of psychotherapeutic change in bulimic women. Evolution Psychiatrique. 2005;70(3):577-594.

41. Poulsen S, Lunn S, Sandros C. Client experience of psychodynamic psychotherapy for bulimia nervosa: An interview study. Psychotherapy: Theory, Research, Practice, Training. 2010;47(4):-469-483.

42. Giorgi A. Phenomenological psychology. In: Smith JA, Harre R, van Langenhove L, editors. Rethinking Psychology. London: Sage;24-42.

43. Palmer R. Hermeneutics. Evanston, IL: North-Western University Press; 1969.

44. Eatough V, Smith JA. Interpretative phenomenological analysis. The Sage Handbook of Qualitative Research in Psychology. 2008:179-194p.

45. Blumer H. Symbolic Interactionism: Perspective and Method. Englewood Cliffs, NJ: Prentice Hall. 1969.

46. Benzies K, Allen M. Symbolic interactionism as a theoretical perspective for multiple method research. Journal of Advanced Nursing. 2001;33(4):541-547.
47. Willig C. Introducing Qualitative Research in Psychology. Open University Press, McGraw-Hill; 2008.

48. Reicher S. Against methodolatry: some comments on Elliott, Fischer and Rennie. British Journal of Clinical Psychology. 2000;39(1):1-6.

49. Zahavi D. Phenomenology, In Moran D, editor. Routledge Companion to Twentieth-Century Philosophy. Routledge, London; 2008.

50. Moran D. Introduction to Phenomenology. London: Routledge. 2000.

51. Smith JA. Reflecting on the development of interpretative phenomenological analysis and its contribution to qualitative research in psychology. Qualitative Research in Psychology. 2004;1(1):39-54.

52. Smith JA, Flowers P, Larkin M. Interpretive Phenomenological Analysis: Theory, Method, and Research. Sage, London; 2009.

53. Heidegger M. Being and Time. Oxford: Blackwell. 1962.

54. Ainsworth MS. Attachments beyond infancy. American psychologist, 1989;44(4):709-716.

55. Maccoby EE. Historical overview of socialization research and theory. Handbook of socialization: Theory and research. 2007;13-41.

56. Allgood SM. Beckert TE, Peterson C. The Role of Father Involvement in the Perceived Psychological Well-Being of Young Adult Daughters: A Retrospective Study. North American Journal of Psychology, 2012;14(1):95-110.

57. Bartholomew K. Avoidance of intimacy: An attachment perspective Journal of Social and Personal relationships, 1990;7(2): 147-178.

58. Collins NL. Working models of attachment: Implications for explanation, emotion, and behavior. Journal of personality and social psychology, 1996;71(4):810-812.

59. Mikulincer M. Attachment working models and the sense of trust: An exploration of interaction goals and affect regulation. Journal of personality and social psychology. 1998;74(5):1209-1224.

60. Levy KN, Blatt SJ, Shaver PR. Attachment styles and parental representations. Journal of personality and social psychology. 1998;74(2):407-419.

61. Sroufe LA. Attachment and development: A prospective, longitudinal study from birth to adulthood. Attachment \& human development. 2005;7(4):349-367.

62. Salzman JP. Primary attachment in female adolescents: Association with depression, self-esteem, and maternal identification. Psychiatry. 59(1):20-33.

63. Seibert AC, Kerns KA. Attachment figures in middle childhood International Journal of Behavioral Development. 2009;33(4):347-355. 